\title{
The Breakdown of Phenols and Related Compounds by Bacteria
}

\author{
BY J. W. CZEKALOWSKI AND B. SKARZYNSKI \\ Departments of Bacteriology and Biochemistry, University of Edinburgh and the \\ Bacteriology Department, Royal Infirmary of Edinburgh
}

SUMMARY: An Achromobacter strain isolated from soil grew on a mineral salt medium containing phenol or various phenol or benzoic acid derivatives as the sole source of carbon. The strain was moderately specific in its action on different classes of aromatic compounds. It did not break down unsubstituted aromatic hydrocarbons and their sulpho-, amino-, nitro- and halogen-derivatives, but did split phenols and carboxy-acids. This ability was limited to mono-cyclic compounds.

The microbicidal properties of phenol, which have been recognized for a long time, are in direct contrast to the fact that there are many types of bacteria which thrive in media containing phenols. It was observed that phenols added to the soil for the purpose of sterilization, instead of destroying the bacteria, actually encouraged growth (Russell \& Hutchinson, 1909 ; Buddin, 1914; Mathews, 1924). The well-known fact that phenols arising in sewage or other decomposing matter fail to prevent the growth of bacteria further indicates the relative insensitivity of certain organisms towards these substances (Fowler, Ardern \& Lockett, 1911).

Fuller investigation has shown that phenols are not only non-lethal to certain bacteria, but that they can even be decomposed by such organisms (Störmer, 1908; Wagner, 1914; Thornton, 1923; Grant \& ZoBell, 1942). Gray \& Thornton (1928), in particular, carried out an extensive research into this problem and isolated from soil various types of bacteria which were capable of using phenol or cresol as the sole source of carbon. These bacteria differed from one another in biological properties and in their ability to grow on different aromatic compounds. They readily tolerated concentrations of phenol up to $0.1 \%$ and some could metabolize aromatic hydrocarbons also. In this connexion it must be mentioned that many authors have described bacterial strains which grow on aromatic hydrocarbons as their only supply of carbon, but these strains were unable to use oxygen-containing aromatic compounds (Söhngen, 1913; Taussen, 1929; Tausz \& Donath, 1930; Frank \& Goodale, 1942). It is obvious that soil bacteria exhibit a wide range of specificity towards different aromatic substances, but this problem awaits fuller investigation.

In the following experiments attempts have been made to investigate in one phenol-tolerant strain the relationship between chemical structure and the use of aromatic compounds by bacteria.

\section{MATERIAL AND METHODS}

Bacteria. Heavily manured garden soil was used as the source of bacteria. The specimens were mixed in 1 g. lots with $100 \mathrm{ml} .0 .05 \%$ phenol. After 3 days incubation at $\mathbf{2 4}^{\circ}$ one loopful was transferred to a mineral salt medium 
containing $0.05 \%$ phenol as the sole source of carbon. In this way bacteria which used phenol were obtained.

The strains were plated on beef-extract peptone agar and single colonies subcultured in mineral salt medium containing $0.05 \%$ phenol for the preparation of pure cultures. The adaptation of selected strains to higher concentrations of phenol was accomplished by subcultivation in mineral salt fluid-medium containing increasing amounts of phenol. The increase in the concentration of phenol was very small and did not exceed $0.005 \%$ for each subculture. The subcultures were made every $4-6$ days, owing to the very slow growth of these bacteria.

Only bacteria actually multiplying in $0.1 \%$ phenol were used. The initial experiments were performed with five bacterial strains, all with the same biological features; for the more detailed experiments only the most actively growing strain was used.

The biological characteristics of the strains are as follows: Motile, Gramnegative bacilli, $2-4 \mu$ by $0 \cdot 5-1 \mu$, non-pigmented on ordinary nutrient agar; optimum temperature for growth about $22-24^{\circ}$; very scanty growth at $37^{\circ}$. After incubation for $24 \mathrm{hr}$. on agar the colonies are about $0.5 \mathrm{~mm}$. in diameter, circular, smooth, greyish white and translucent. After 5 or 6 days the colonies are $3-5 \mathrm{~mm}$. in diameter, raised, greyish, opaque, with smooth surfaces and regular edges. Uniform turbidity in broth with a granular deposit; on potato a greyish confluent growth; good growth on McConkey's medium, none on desoxycholate citrate agar medium. Milk slightly curdled, but no change in pH noticed. Gelatin liquified in $12 \mathrm{hr}$. Of the sugars examined (arabinose, rhamnose, xylose, glucose, mannose, lactose, maltose, sucrose, starch and inulin) only glucose was slightly fermented. No fermentation of alcohols (glycerol, adonitol, mannitol, dulcitol, sorbitol), or glucosides (salicin and aesculin), or of inositol. Indole not produced, and the Voges-Proskauer and methyl red tests negative.

On the basis of these biological characteristics the strains used were identified as belonging to the Achromobacter genus (Topley \& Wilson, 1936).

Media. Two kinds of medium were used: (a) Nutrient (ox-heart extract peptone) agar; this was used for isolation of pure cultures, for standard cultures and for viability tests. (b) Liquid mineral salt medium based on a recipe of Gray \& Thornton (1928) with the following composition: $\mathrm{MgSO}_{4}, 0.2 \mathrm{~g}$.; $\left(\mathrm{NH}_{4}\right)_{2} \mathrm{SO}_{4}, 1.0$ g.; $\mathrm{NaCl}, 0.1$ g.; $\mathrm{KH}_{2} \mathrm{PO}_{4}, 1.76$ g.; $\mathrm{CaCl}_{2}, 0.1$ g.; $\mathrm{Na}_{2} \mathrm{HPO}_{4}$ (anhydrous), 2.88 g.; $\mathrm{FeCl}_{\mathbf{8}}, \mathbf{0 \cdot 0 2} \mathrm{g}$; ; distilled water $1000 \mathrm{ml}$.

In some experiments requiring unbuffered medium Gray \& Thornton's original formula was followed.

Because precipitates form in the defined medium during autoclaving it was sterilized by filtration through Seitz-type pads. This medium, supplemented with $0.1 \%$ of various aromatic compounds as the source of carbon, was used in the experiments on growth and adaptation to different aromatic compounds of the strains tested.

Inoculation. The synthetic media containing various aromatic hydrocarbons were inoculated with $0.01 \mathrm{ml}$. of a 14-day-old culture of the Achromobacter sp. grown on a medium containing $0.1 \%$ phenol. 
The measurement of bacterial growth. The growth of cultures was measured turbidimetrically, using a Spekker photoelectric absorptiometer, with smoky filters no. H. 508. Readings were made against distilled water. The intensity of turbidity expressed in units was read from a standard turbidity curve, which for comparison was calibrated against standard opacity tubes made according to Brown (1919).

In some experiments of long duration the turbidity alone was not an adequate measure because it did not exclude dead bacteria. To overcome this difficulty we counted the viable organisms by the plating method in addition, using an ordinary nutrient agar. The figures given on the viability curve (Fig. 1) were obtained by taking as an arbitrary unit the value recorded on the day before that on which a decrease was observed in the number of viable bacteria and expressing all figures obtained on subsequent days in terms of this unit.

Some of the aromatic compounds tested were only slightly water-soluble and produced opalescence in the medium, thus rendering turbidimetric estimations impossible. In these cases the bacterial growth was followed by direct counts.

Chemical estimations. A glass electrode was used for $\mathrm{pH}$ measurements.

Phenol was estimated by Theis \& Benedict's colorimetric method (Theis \& Benedict, 1924). All test compounds were purified and their purity was checked by melting- or boiling-point determination.

\section{RESULTS}

The initial experiments with the five different strains of Achromobacter sp. showed that all grew readily in $\mathbf{0 . 1} \%$ phenol as the sole source of carbon; $0.15 \%$ phenol prevented growth, but did not kill the bacteria until cultures were 10 days old; $0 \cdot 2 \%$ phenol was markedly bactericidal in $48 \mathrm{hr}$.

The same bacteria grew in the presence of glucose, acetate and citrate two to four times as abundantly as in the phenol medium. It seems that these aliphatic substances are a preferred source of carbon and that the use of phenol presents merely an alternative (emergency) mechanism of the bacterial cell, manifested distinctly only in the absence of easily metabolized aliphatic substances. When grown in medium containing $0.2 \%$ of glucose and $0.1 \%$ of phenol the strains used both substances simultaneously, but the breakdown of phenol was markedly decreased and the number of bacteria increased much faster than when phenol alone was the substrate. The multiplication of bacteria on phenol proceeded only when there was free access of oxygen.

The growth of bacteria on phenol as the sole source of carbon is slow during the first 2 days, passes during the next 7 days through the phase of logarithmic multiplication and reaches its peak in 10 days. The stationary phase lasts about 3 weeks, after which there is a slow decrease in the number of living bacteria (Fig. 1). The rate of growth on phenol was always reproducible if the same conditions were maintained.

The rate of disappearance of phenol in the medium is at first slow, but begins 
to be pronounced simultaneously with the phase of rapid multiplication of bacteria and increases progressively during the stationary phase as well (Fig. 1).

The Achromobacter strains, when growing on unbuffered mineral salt medium with an initial $\mathrm{pH}$ of $7 \cdot 6$, brought the $\mathrm{pH}$ down to $6 \cdot 0$ during the logarithmic

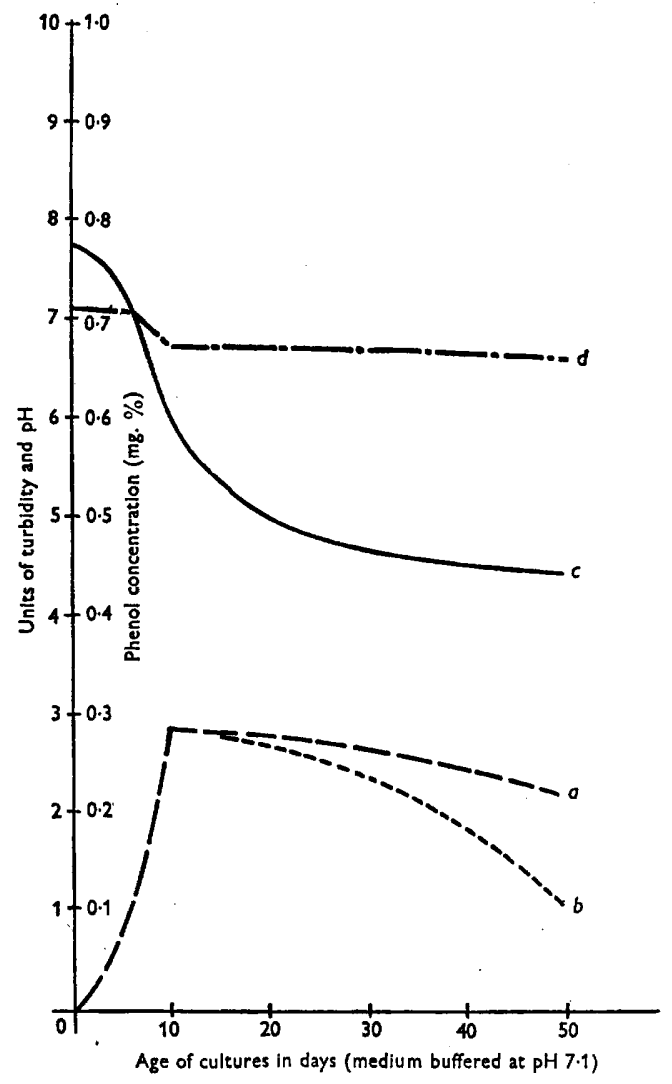

Fig. 1. $a=$ bacterial growth estimated turbidimetrically; $b=$ bacterial growth estimated by viable count; $c=$ phenal concentration; $d=$ pH of culture.

phase and maintained it there during the stationary phase. The lowering of pH was much more pronounced in cultures growing on unbuffered media containing glucose instead of phenol. The use of phenol and the rates of bacterial multiplication were independent of $\mathrm{pH}$ within the limits of 6.0-7/6. Most of our experiments were performed in buffered media at pH 7.0.

Table 1 shows the effect of various aromatic compounds as the sole source of carbon on one Achromobacter strain.

This strain is highly selective in using different aromatic compounds. It cannot use the unsubstituted aromatic compounds like benzene or toluene, either as free hydrocarbons or as their sulphonic acids, nor does the introduction into the benzene ring of chloro-, nitro, or amino-groups make the 
substances susceptible to breakdown by these bacteria. Hydrogenation of the benzene ring, however, does so, as was shown in the case of cyclohexane which is itself a good source of carbon. Nearly all the mono-, di- and tri-phenols investigated were good sources of carbon. It seems that the presence of free phenolic groups is essential. The phenolic ethers were not attacked by this strain, though the esters of phenol were readily used as a source of carbon.

Table 1. Use of various benzene derivatives by an Achromobacter strain

\begin{tabular}{|c|c|c|c|}
\hline Compound & $\begin{array}{c}\text { Bacterial } \\
\text { growth after } \\
5 \text { days }\end{array}$ & Compound & $\begin{array}{c}\text { Bacterial } \\
\text { growth after } \\
5 \text { days }\end{array}$ \\
\hline Benzene & 一 & Orcinol & +++ \\
\hline Toluene & - & Pyrogallol & + \\
\hline Benzenesulphonic acid & - & Benzoic acid & $++t+$ \\
\hline$p$-Toluenesulphonic acid & - & Benzamide & + \\
\hline Cyclohexane & + & o-Nitrobenzoic acid & \pm \\
\hline Cyclohexanol & + & o-Hydroxybenzoic acid & $++t+$ \\
\hline Monochlorobenzene & - & $p$-Hydroxybenzoic acid & \pm \\
\hline Nitrobenzene & - & 3, 5-Dihydroxybenzoic acid & $++\dot{t}+t$ \\
\hline Aminobenzene & - & o-Aminobenzoic acid & ++ \\
\hline Phenol & +++ & $p$-Aminobenzoic acid & \pm \\
\hline Phenyl benzoate & $++t+$ & Phthalic acid & $=$ \\
\hline Phenyl acetate & +++ & Terephthalic acid & - \\
\hline Phenyl sulphate & +++ & Phenylacetic acid & ++++ \\
\hline Phenylmethylether & - & Diphenylacetic acid & +++ \\
\hline Phenylethylether & - & Benzyl alcohol & +++ \\
\hline Diphenylether & - & Benzhydrol & \pm \\
\hline o-Cresol & +++ & Benzophenone & 二 \\
\hline$m$-Cresol & ++ & Benzil & - \\
\hline$p$-Cresol & ++ & $p$-Hydroxybenzaldehyde & \pm \\
\hline 3, 4-Xylen-1-ol & ++ & Naphthalene-2-sulphonic acid & 二 \\
\hline 3, 5-Xylen-1-ol & 一 & $\alpha$-Naphthol & - \\
\hline o-Dihydroxybenzene & +++ & $\beta$-Naphthol & - \\
\hline$m$-Dihydroxybenzene & + & 1-Hydroxy-5-naphthoic acid & - \\
\hline$p$-Dihydroxybenzene & - & & \\
\hline
\end{tabular}

Probably the enzymic system of the bacterial cell contains esterases which split the ester linkage, rendering the free phenol available to the bacterial cell, but there does not appear to be splitting of the ethers.

Quantitative estimations of bacterial growth showed that there were distinct differences in the rates of multiplication with different phenols. Although the limited accuracy of the method demands that conclusions should be drawn with caution, the results show that $o$-di-phenol (catechol) is used much better than $m$-di-phenol (resorcinol); $p$-di-phenol (hydroquinone) was not attacked by our Achromobacter strain. Fig. 2 shows the multiplication rate in different phenols.

Substitution of alkyl-groups in phenol had in some instances a marked effect on the availability of the compounds for our bacteria. The rate of growth with $p$ - and $m$ - methyl-phenol (cresol) is of the same order of magnitude as the rate of growth with phenol, but is lower than the rate of growth with o-methyl- 
phenol. The introduction of a methyl-group into resorcinol enhances its use by bacteria, orcinol being a much better source of carbon than resorcinol. There is no difference between the multiplication rate with 3, 4-xylen-1-ol and with phenol, but 3, 5-xylen-1-ol is not used at all.

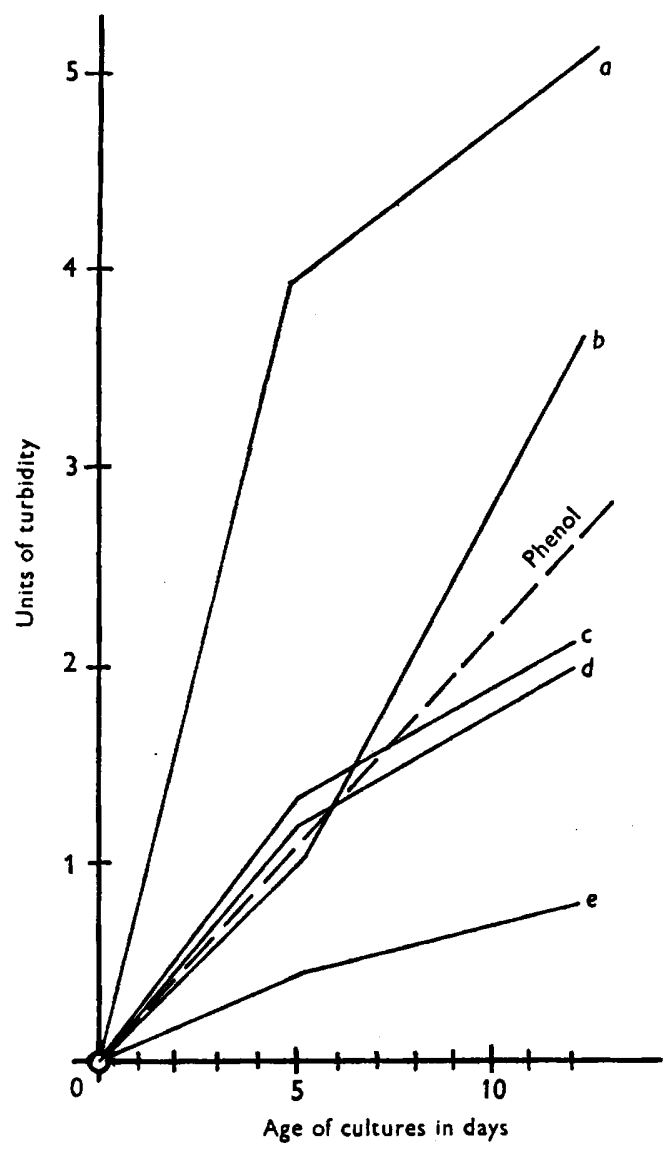

Fig. 2. $a=o$-cresol; $b=m$-cresol; $c=$ catechol; $d=p$-cresol; $e=$ resorcinol.

When a carboxyl-group is introduced into the benzene ring, the compound supports growth of our bacterium. The rate of multiplication on benzoic, phenylacetic and salicylic acids is distinctly higher than on phenol. However, in the case of carboxylic acid derivatives of benzene we must take account of many exceptions which make an explanation of the relationship between chemical structure and use by bacteria more difficult to formulate. For example the dicarboxylic acids, phthalic and terephthalic acids, were not used by our strain.

$p$-Aminobenzoic acid permits only very slight growth of the bacterium. This cannot depend upon the presence of an amino-group on the benzene ring, because the $o$-homologue of this acid is readily used. It seems, rather, that 
para-substitution in benzoic acid in general diminishes the availability of the compound for the bacterial cell (Fig. 3).

The alcoholic group also renders the benzene ring susceptible to the action of the bacterium, but this is not a general rule. Benzyl-alcohol is used, but not

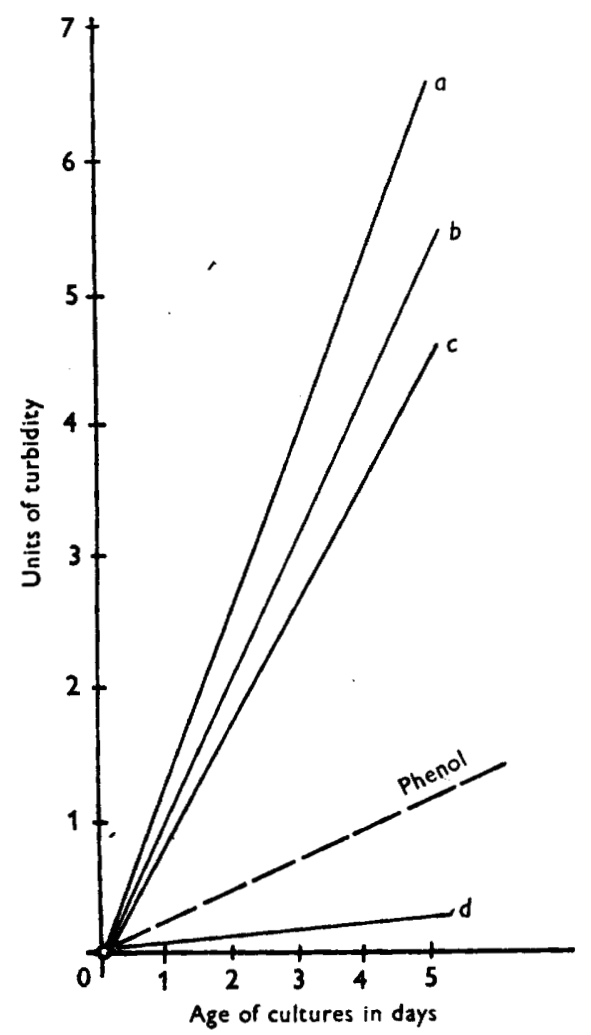

Fig. 3. $a=$ phenylacetic and phenylbenzoic acids; $b=$ phenyl benzoate; $c=$ benzyl alcohol; $d=p$-aminobenzoic acid.

benzhydrol. It seems that the carbonyl-group does not alter the resistance of the benzene ring, since neither benzophenone nor benzil are used.

Only mono-cyclic aromatic compounds were susceptible to bacterial action; all the hydroxy- and carboxy-derivatives of naphthalene investigated failed to support bacterial growth.

The authors wish to express their gratitude to Prof. T. J. Mackie, Prof. G. F. Marrian and Dr W. R. Logan for their hospitality and interest throughout the experiments.

\section{REFERENCES}

Brown, H. C. (1919). Further observations on the standardisation of bacterial suspensions. Indian J. med. Res. 7, 238.

Budorn, W. (1914). Partial sterilisation of soil by volatile and non-volatile antiseptics. J. agric. Sci. 6, 417 . 
Fowler, G. J., ARdern, E. \& LocketT, W. T. (1911). The oxidation of phenol by certain bacteria in pure culture. Proc. Roy. Soc. B, 83, 149.

Grant, C. W. \& ZoBele, C. E. (1942). Oxidation of hydrocarbons by marine bacteria. Proc. Soc. exp. Biol., N.Y., 51, 266.

Gray, P. H. H. \& Thornton, H. G. (1928). Soil bacteria that decompose certain aromatic compounds. $\mathrm{Zbl}$. Bakt. (2. Abt.), 73, 74.

Mathews, A. (1924). Partial sterilisation of soil by antiseptics. J. agric. Sci 14, 1.

Russell, E. J. \& Hutchinson, H. B. (1908-10). The effect of partial sterilisation of soil on the production of plant food. J. agric. Sci. 3, 111.

Söhngen, N. L. (1913). Benzin, Petroleum, Paraffinöl und Paraffin als Kohlenstoffund Energie-quelle für Mikroben. Zbl. Bakt. (2. Abt.), 37, 595.

Störmer, K. (1908). Ueber die Wirkung des Schwefelkohlenstoffs und ähnlicher Stoffe auf den Boden. Zbl. Bakt. (2. Abt.), 20, 282.

Taussen, W. O. (1929). Über die Oxydation der Benzolkohlenwasserstoffe durch Bakterien. Planta, 7, 735.

Tausz, J. \& Donath, P. (1930). Über die Oxydation des Wasserstoffs und der Kohlenwasserstoffe mittels Bakterien. Hoppe-Seyl. Z. 190, 141.

Theis, R. C. \& Benedict, S. R. (1924). The determination of phenols in the blood. J. biol. Chem. 61, 67 .

Thornton, H. G. (1923). The destruction of aromatic antiseptics by soil bacteria. Nature, Lond., 111, 347.

Topley, W. W. C. \& Wilson, G. S. (1936). Principles of Bacteriology and Immunity, 2nd ed. p. 502. London: Arnold.

WAGNer, R. (1914). Ueber Benzol-Bakterien. Z. f. GärPhysiol. 4, 289.

(Received 13 January 1948) 